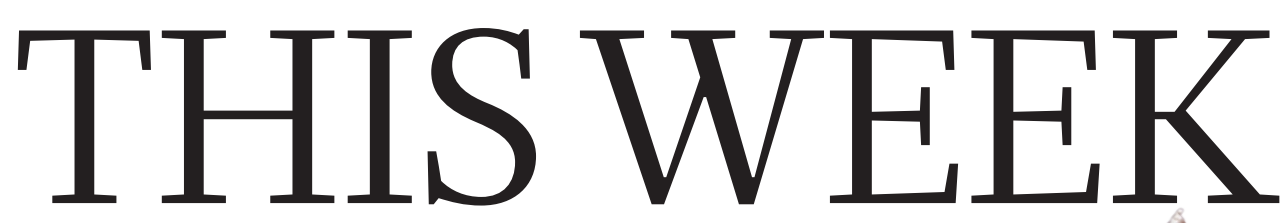

EDITORIALS

WORLD VIEW Policy-makers must engage with the reality of geoengineering $\mathbf{p . 1 5 9}$
WEIGHT LOSS A true measure of the mass of extinct beasts $\mathbf{p . 1 6 0}$
BLUEDANUBE The cultural

flow of the river 40,000 years ago $\mathbf{p} .161$

\title{
Reply to all
}

Scientists discussing their work through written media, including e-mail, should be aware that they could at any time be asked to reveal their conversations.

"Y ou are commanded to produce... any and all documents data, and/or communications." Towards the end of last year, those orders appeared in a subpoena that landed at the Woods Hole Oceanographic Institution in Massachusetts. The energy firm BP demanded that Woods Hole produce e-mails and other documents related to its research on the 2010 Deepwater Horizon oil spill in the Gulf of Mexico. Woods Hole fought the sweeping request, but a US district court has now forced researchers at the institute to surrender thousands of e-mails. That decision has disturbing implications for science in the United States, although the situation is perhaps not as dire as some have warned.

The demand for the e-mails emerged from a huge lawsuit, in which BP is being sued by the US government and others affected by the oil spill. As part of that suit, the company faces fines of up to US $\$ 4,300$ per barrel of oil spilled, which could amount to more than $\$ 17$ billion if the court sides with government estimates for the size of the spill. BP argues that these estimates - much higher than the company's own - rely heavily on research conducted by Woods Hole. And it claims that aspects of the work involve "puzzling, apparently arbitrary, suspiciously offsetting, and highly significant decisions by Woods Hole researchers".

Woods Hole is not a party to the lawsuit, but it did have a contract with the government during the first month of the spill to measure how much oil and gas was spewing from the broken well. After that, researchers from the institute worked to refine their analyses and publish papers on the spill in academic journals. One Woods Hole scientist also participated in a governmental panel asked to estimate the size of the spill.

To defend itself in court, BP contends that it needs more than just the raw data collected by Woods Hole and a description of the methods used by its researchers. Woods Hole turned over much of the data and analysis tools to BP on its original request, but it fought against surrendering confidential academic communications, arguing that those have been protected in the past by courts, which have recognized the importance of 'scholastic privilege'. Indeed, the judge who ruled over Woods Hole's arguments recognized the principle of scholastic privilege regarding confidentiality, but only up to a point. She found that BP had a compelling need for the Woods Hole e-mails and other communications for the period before the government-led group issued its report in March last year. The e-mails handed to BP could be made public if the case goes to trial.

But the judge did not allow BP access to communications after that time, when the Woods Hole researchers were preparing academic publications. "If BP gains access to the analysis documents for these article [sic], that could hamper future research efforts," she said.

The decision pleased neither BP nor Woods Hole. BP appealed, seeking all the documents it requested, but was unsuccessful. Woods Hole contends that surrendering the e-mails will have a chilling effect

on science, by forcing researchers to avoid topics that could become subjects of litigation. Is the institute right? It is hard to judge the scale of the potential damage the decision could cause. Even well before the subpoena, some researchers declined to study the spill, in part because

"It is hard to judge the scale of the potential damage the decision could cause." Researchers who choose to study topics that have multiple and conflicting implications for powerful special interests must go in with their eyes open and be aware of the risks. Not only have Woods Hole researchers had to surrender their e-mails, they have also spent hundreds of hours complying with the subpoena. And the case has drained considerable funds from the non-profit institution through lawyers' fees and lost staff time.

The decision provides yet another reminder that scientists should not regard e-mails as being private. Whether by theft or by court order, such communications can be taken away. Think before you press Send.

\section{Calling Nordic mentors}

Cvery year, Nature awards prizes to senior researchers in the nnatural sciences for sustained and outstanding scientific mentoring of young researchers. There are two prizes, each worth $€ 10,000$ (US\$12,500): one for lifetime achievement, one for mid-career achievement.

The competitions are organized on a country or regional basis. We shall give this year's accolades to researchers who live in the Nordic countries: Sweden, Norway, Denmark, Finland, Iceland and Greenland.

Nominations are now open, with a deadline of Monday 13 August. Each applicant should be nominated by five people who have been mentored by her or him over different periods. The forms for nominations, and other essential details about the competition, including the list of judges, can be found at go.nature.com/bxzc9y. 